\title{
Curcumin inhibits cholesterol uptake in Caco-2 cells by down-regulation of NPC1L1 expression
}

\author{
Dan Feng, Lena Ohlsson and Rui-Dong Duan*
}

\begin{abstract}
Background: Curcumin is a polyphenol and the one of the principle curcuminoids of the spice turmeric. Its antioxidant, anti-cancer and anti-inflammatory effects have been intensively studied. Previous in vivo studies showed that administration of curcumin also decreased cholesterol levels in the blood, and the effects were considered to be related to upregulation of $L D L$ receptor. However, since plasma cholesterol levels are also influenced by the uptake of cholesterol in the gut, which is mediated by a specific transporter Niemann-Pick Cl-like 1 (NPC1L1) protein, the present study is to investigate whether curcumin affects cholesterol uptake in the intestinal Caco-2 cells.

Methods: Caco-2 cells were cultured to confluence. The micelles composed of bile salt, monoolein, and ${ }^{14} \mathrm{C}$ cholesterol were prepared. We first incubated the cells with the micelles in the presence and absence of ezetimibe, the specific inhibitor of NPC1L1, to see whether the uptake of the cholesterol in the cells was mediated by NPC1L1. We then pretreated the cells with curcumin at different concentrations for $24 \mathrm{~h}$ followed by examination of the changes of cholesterol uptake in these curcumin-treated cells. Finally we determined whether curcumin affects the expression of NPC1L1 by both Western blot analysis and QPCR quantification.

Results: We found that the uptake of radioactive cholesterol in Caco-2 cells was inhibited by ezetimibe in a dosedependent manner. The results indicate that the uptake of cholesterol in this study was mediated by NPC1L1. We then pretreated the cells with 25-100 $\mu \mathrm{M}$ curcumin for $24 \mathrm{~h}$ and found that such a treatment dose-dependently inhibited cholesterol uptake with $40 \%$ inhibition obtained by $100 \mu$ M curcumin. In addition, we found that the curcumininduced inhibition of cholesterol uptake was associated with significant decrease in the levels of NPC1L1 protein and NPC1L1 mRNA, as analyzed by Western blot and qPCR, respectively.
\end{abstract}

Conclusion: Curcumin inhibits cholesterol uptake through suppression of NPC1L1 expression in the intestinal cells.

\section{Introduction}

Elevated plasma cholesterol levels constitute a major risk factor for atherosclerosis and coronary heart diseases [1]. The levels of plasma cholesterol are influenced by de novo biosynthesis, absorption in the gut, and the removal of cholesterol from the blood [2]. The intestine plays a major role in regulating cholesterol homeostasis and about $36 \%$ reductions of plasma cholesterol could be achieved by total inhibition of cholesterol absorption [3]. Absorption of cholesterol is a multi-step process in which cholesterol is micellized by bile acids in the intestinal lumen, taken up by the enterocytes, assembled into lipoproteins, and transported to the lymph and the circula-

* Correspondence: Rui-dong.duan@med.lu.se

${ }^{1}$ Gastroenterology and Nutrition Laboratory, Biomedical Center B11, Institution of Clinical Sciences, University of Lund, Lund, Sweden Full list of author information is available at the end of the article tion. Niemann-Pick C1-like 1(NPC1L1) protein has been identified as a specific transporter for cholesterol uptake at the surface of plasma membrane [4]. Ezetimibe is a well-known inhibitor of NPC1L1 and has been widely used as an effective cholesterol-lowering drug for treating patients with hypercholesterolemia[5].

Curcumin is the major constituent of turmeric curcuminoids and has been found to have antioxidant, antitumor, anti-inflammatory properties [6-8]. Besides these well-known effects, curcumin was also found to affect lipid metabolism. More than 30 years ago, Rao et al showed that administration of curcumin decreased cholesterol levels in the blood and liver in normal animals [9]. Similar reductions were also identified thereafter in diabetic animals and animals fed high fat [10-12] and in healthy humans, varied with the dose, age and the period of administration [13-15]. The mechanism underlying the 
hypocholesterolemic effect may be related to the upregulation of LDL receptor [16,17]. Since plasma cholesterol levels are also influenced by absorption of cholesterol in the gut, we, in the present study, addressed a question whether curcumin affects the cholesterol uptake in the enterocytes.

\section{Materials and methods Materials}

Caco-2 cells were obtained from American Tissue Culture Collection. The Modified Eagle Medium (DMEM), M199 medium, heat-inactivated fetal bovine serum (FBS), 1\% non-essential amino acids were purchased from either Invitrogen or Sigma-Aldrich (Stockholm, Sweden). $\left[{ }^{14} \mathrm{C}\right]$ cholesterol $(50 \mathrm{mCi} / \mathrm{mmol})$ was purchased from American Radiolabeled Chemicals Inc (St. Louis, MO, USA). Curcumin (purity $>98 \%$ ) was purchased from Sigma-Aldrich. NPC1L1 antibody was purchased from Santa Cruz (Santa Cruz, USA). QT-PCR kit was obtained from Bio-Rad (Stockholm, Sweden). Primers used in quantification of mRNA of NPC1L1 by qPCR were synthesized from DNA Technology (Rysskov, Denmark). Ezetimibe (purity >95\%) was kindly provided by Schering-Plough Research Institute (Kenilworth, USA).

\section{Preparation of delipidized fetal bovine serum and cholesterol micellar solutions}

The preparation of delipidized FBS was according to Gibson et al [18]. In brief, $20 \mathrm{~g}$ thixotropic gel powder (Cabo-sil, Kodak) was added to 1 liter FBS and stirred overnight at $4^{\circ} \mathrm{C}$. The mixture was then centrifuged at 15,000 rpm at $4^{\circ} \mathrm{C}$ for $1 \mathrm{~h}$ and the supernatant was collected and sequentially filtered through $0.20 \mu \mathrm{m}$ filter. For preparing micellar cholesterol solutions, M199 culture media containing $3 \mathrm{mM}$ sodium taurocholate, $30 \mu \mathrm{M}$ monoolein and $1 \mathrm{nM}\left[{ }^{14} \mathrm{C}\right]$ cholesterol $\left(1.25 \times 10^{5} \mathrm{dpm}\right)$ were mixed and sonicated, as reported by Field et al [19]. The micellar solution was then passed through a $0.20 \mu \mathrm{m}$ filter and kept at $37^{\circ} \mathrm{C}$ until use.

\section{Cell culture and stimulation}

Caco- 2 cells were cultured in 6 well plate in DMEM, containing 10\% FBS, $1 \%$ penicillin-streptomycin, $2 \mathrm{mM} \mathrm{L-}$ glutamate, $1 \%$ non-essential-amino acids to confluence as described by Eckhardt et al [20]. Prior to experiment, the culture medium with $10 \%$ FBS was replaced with the medium containing the delipidized FBS, followed by incubating the cells for $24 \mathrm{~h}$. The cells were then washed three times with M199 buffer, and then incubated with fresh medium containing the cholesterol micelles for $2 \mathrm{~h}$. The medium was then removed and the cells were washed three times with ice-cold PBS. After centrifugation, the cell pellets were dissolved in $0.5 \mathrm{ml}$ of $0.1 \mathrm{M}$ $\mathrm{NaOH}$ and an aliquot of $0.1 \mathrm{ml}$ of the lysate was taken for liquid scintillation counting. The protein concentration of the lysate was quantified by a kit from Bio-Rad and the results of incorporated cholesterol into Caco-2 cells were expressed as $\mathrm{dpm} / \mathrm{mg}$ protein. To confirm that the uptake of cholesterol under this experimental conditions was mediated by NPC1L1 not passive diffusion, some cells were pretreated with ezetimibe, the inhibitor of NPC1L1, for $2 \mathrm{~h}$. The changes of cholesterol uptake induced by ezetimibe were examined.

To study the effects of curcumin on cholesterol uptake, curcumin was freshly dissolved in dimethyl sulfoxide (DMSO) at different concentrations and immediately diluted in the DMEM culture medium as described above. The cells were pretreated with curcumin with different concentrations for $24 \mathrm{~h}$. The final concentration of DMSO in the medium was $0.1 \%$ and the control cells were incubated with $0.1 \%$ DMSO only. After the pretreatment, the medium was removed and the cells were washed three times with ice-cold PBS, followed by incubation with the cholesterol micelles as described above. The cholesterol uptakes in the cells with and without curcumin treatment were compared.

\section{RNA estimation by real time quantitative RT-PCR(QT-PCR)}

RNA was extracted from the cells using TRIzol reagents and converted to cDNA by a kit from Fermentas (Helsingborg, Sweden). The primers used in qPCR to quantify the mRNA of NPC1L1 were shown in Table 1. The cDNA isolated from the cells was mixed with the appropriate primers and $2 \times$ SYBR Green PCR master mix (Bio-Rad) in $20 \mu \mathrm{l}$. Real-time RT-PCR was performed using the BioRad iCycler system. The thermal cycler program was as follows: holding for $3 \mathrm{~min}$ at $95^{\circ} \mathrm{C}$ for one cycle, followed by amplification of cDNA for 45 cycles with melting for $15 \mathrm{~s}$ at $95^{\circ} \mathrm{C}$, and annealing and extension for $1 \mathrm{~min}$ at $60^{\circ} \mathrm{C}$. The mass of PCR products generated was estimated after each PCR cycle, and threshold cycle number is determined in the exponential phase of the curve. The values were normalized using GAPDH as an endogenous internal standard. The relative expression of the gene was

Table 1: Primers used in this study.

\begin{tabular}{ll}
\hline Primer & Sequence \\
\hline Human NPC1L1-F & \\
Human NPC1L1-R & $5^{\prime}$-TATGGTCGCCCGAAGCA-3' \\
& $5^{\prime}-$ \\
& TGCGGTTGTTCTGGAAATACT \\
GAPDH-F & G' $^{\prime}-$ \\
& CATGAGAAGTATGACAACAG \\
& CCT-3' \\
GAPDH-R & $5^{\prime}-$ \\
& AGTCCTTCCACGATACCAAA \\
& GT-3' \\
\hline
\end{tabular}


calculated using the comparative threshold cycle (Ct) method.

\section{Western blot}

The cells were lysed and the cell free extract was prepared as described [21]. Proteins $(40 \mu \mathrm{g})$ in cell lysate were subjected to $7.5 \%$ SDS PAGE. The resolved proteins in the gel were transferred to a nitrocellulose membrane electrophoretically overnight. The membranes were incubated with anti-NPC1L1 antibody (1:5000) and then with second antibody (1:50000) conjugated with horseradish peroxidase. The specific NPC1L1 bands (145 kD) were identified by enhanced chemiluminescence advance reagent. The membranes were then stripped and reprobed with anti-actin antibody as a loading control.

\section{Statistical analysis}

The results are presented as mean \pm S.E.M. Statistical analyses were performed using one-way analysis of variance (ANOVA) followed by the Bonferroni posttest for multiple comparisons. Differences were considered significant at $P<0.05$.

\section{Results}

Uptake of cholesterol in Caco-2 cells was inhibited by ezetimibe

Because uptake of cholesterol in the intestinal tract was mediated by NPC1L1 whose functions can be inhibited specifically by ezetimibe $[4,5]$, we first examined whether cholesterol uptake in Caco-2 cells under the experimental conditions was related to the functions of NPC1L1. The answer is positive. As shown in Fig. 1, the cholesterol uptake was dose dependently inhibited by ezetimibe.

\section{Curcumin inhibited cholesterol uptake in Caco-2 cells}

We then addressed a question whether curcumin can inhibit cholesterol uptake. After pretreating the cells with curcumin for $24 \mathrm{~h}$, we found that cholesterol uptake in Caco-2 cells was decreased with the increasing concentrations of curcumin (Fig. 2). The threshold concentration of curcumin is about $25 \mu \mathrm{M}$ and at $100 \mu \mathrm{M}$ curcumin decreased cholesterol uptake by about $40 \%$.

\section{The effects of curcumin were associated with decreased NPC1L1 protein expression}

We then further studied whether curcumin could influence the levels of NPC1L1 in the intestinal cells. As shown in upper panel of Fig. 3, pretreatment of the cells with different concentrations of curcumin for $24 \mathrm{~h}$ significantly attenuated NPC1L1 protein levels. No similar changes could be identified for the levels of actin. To distinguish whether the effect was caused by an increased degradation or a decreased biosynthesis, the levels of mRNA of NPC1L1 after treating the cells with curcumin were quantified. As shown in the lower panel of Fig. 3, curcumin induced a dose-dependent reduction of

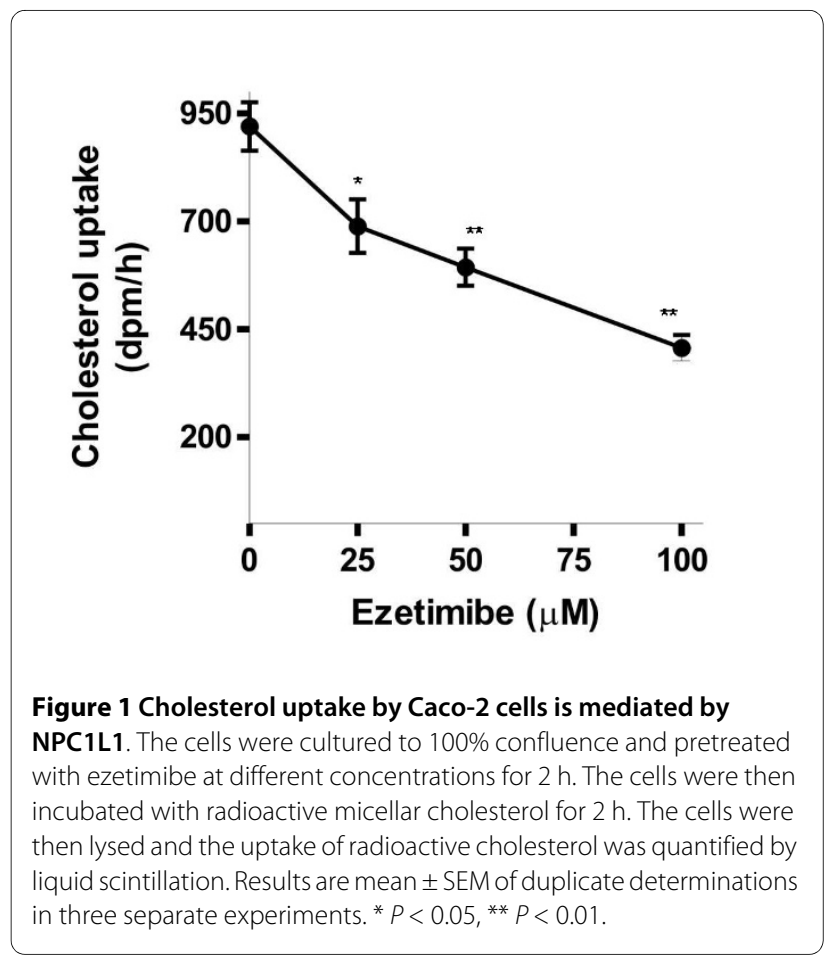

NPC1L1 mRNA, as normalized with that of control gene GAPDH. About $50 \%$ inhibition could be identified by 50 $\mu \mathrm{M}$ curcumin.

\section{Discussion}

Previous studies in animals and humans have shown that administration of curcumin decreased the cholesterol levels in blood (11-14). The mechanism underlying the effects was considered to be related to the increased

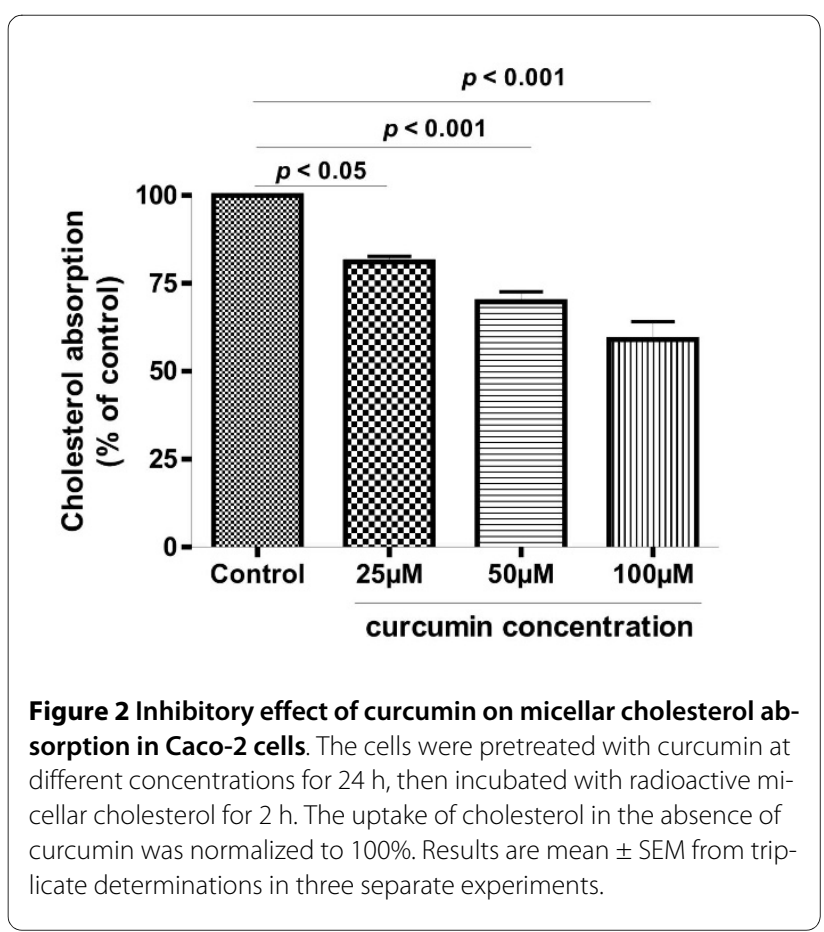




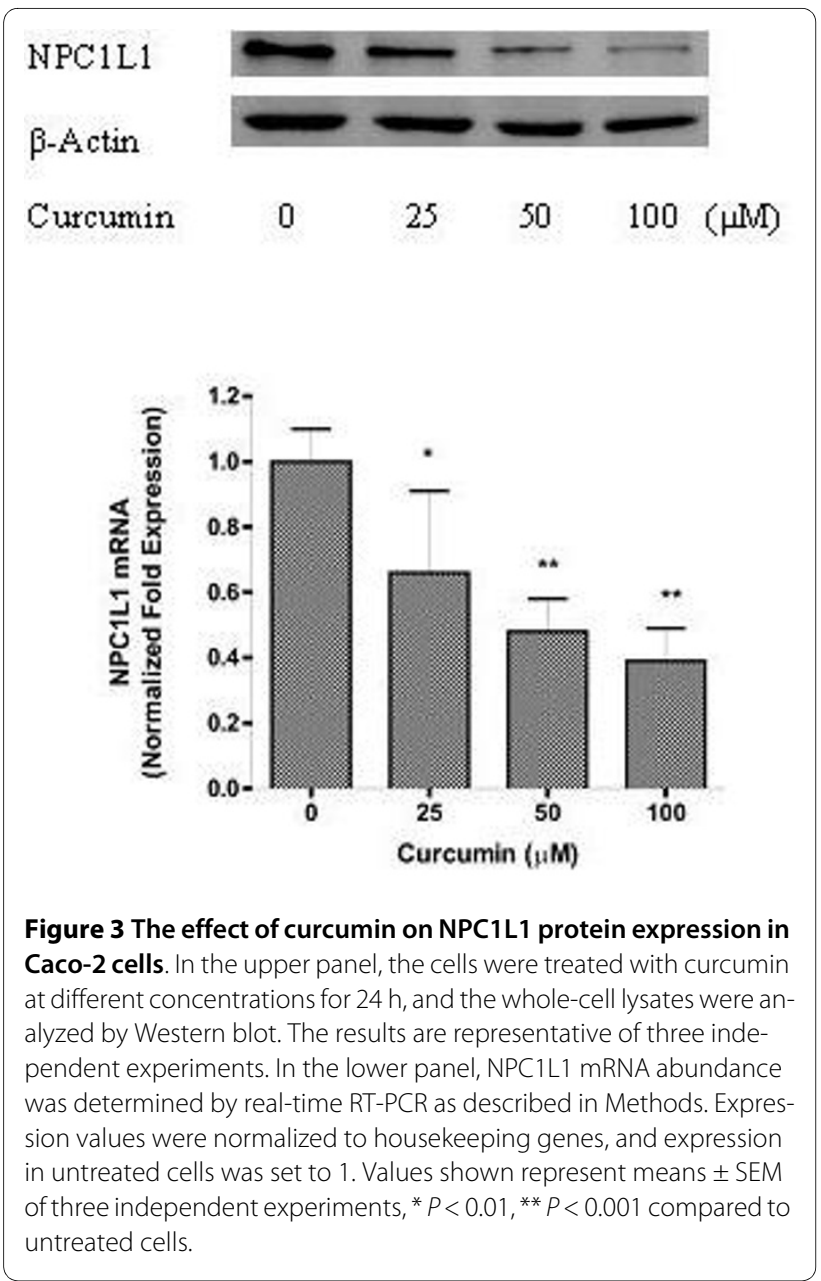

expression of LDL receptor [16,17]. Since intestinal absorption of cholesterol also affects the levels of cholesterol in the blood, whether uptake of cholesterol in the enterocytes can be affected by curcumin is therefore an important question to be studied. Our results for the first time show that curcumin has inhibitory effects on cholesterol uptake and the inhibition is mediated by down-regulation of NPC1L1 expression. The conclusion is supported by the evidence from 3 lines in the present study. First, the uptake of cholesterol into Caco-2 cells was a process mediated by NPC1L1, since it could be inhibited in a dose-dependent manner by ezetimibe, a specific inhibitor of NPC1L1. Second, the NPC1L1 protein in the cells was decreased by treating the cells with curcumin. And third, the reduced NPC1L1 protein was most likely resulted from a decreased expression, as a significant decrease of NPC1L1 mRNA was demonstrated by curcumin treatment in a dose dependent manner.

Curcumin is one of the most intensively studied plant components and most of the studies are focused on its antiinflammatory and anticancer effects [22-24]. However, its hypocholesterolemic effects have documented for more than 30 years [9-15]. Most of the previous studies were performed in animal models followed by analysis of the cholesterol levels in the blood and liver. The most consistent finding from the previous studies is a decreased cholesterol level in the blood. The mechanism for such a decrease was suggested to be mediated by an upregulation of LDL receptor $[16,17]$. The present work demonstrated a novel effect of the component in the gut, i.e. to inhibit the expression of NPC1L1 in the enterocytes. Our results indicate that curcumin can decrease the cholesterol levels by two mechanisms, one in the intestine to inhibit the uptake via NPC1L1 transporter, and the other in the blood to increase the clearance by LDL receptor. Considering the poor absorption in the gut and low concentration of curcumin in the blood [24], its effect in the intestinal tract might be of more physiological implications than its systemic effects.

NPC1L1 is a crucial transporter for cholesterol uptake. Understanding the regulation of its expression is of importance in human health and disease. It is only recently that several studies showed that diet with low cholesterol and low fat increased the NPC1L1 expression in the small intestine in hamster [25]. A few dietary factors such as phytosterol [26], PUFA [27] and dietary supplement probiotics [28] may also affect expression of NPC1L1. Although the molecular signals regulating the expression of NPC1L1 is not clear, several nuclear receptors such as sterol responsive element binding protein 2(SREBP2), LXR and HNF4 $\alpha$ might be involved [29]. Overexpression of SREBP2 results in an enhanced transcription of NPC1L1. Curcumin has been shown to affect the functions of about 50 transcriptional factors $[22,30]$. Whether some of these factors are linked to the nuclear receptor, leading to the inhibition of the expression of NPC1L1 requires further investigation in the future.

\section{Conclusion}

Curcumin, the dietary polyphenol isolated from turmeric can inhibit cholesterol uptake in the enterocytes by inhibiting the expression of NPC1L1, the key transporter of cholesterol in the cell membrane.

\section{Competing interests \\ The authors declare that they have no competing interests.}

\section{Authors' contributions}

DF is the major investigator involved in the bench work, data acquisition, analysis and manuscript preparation. LO and RDD are involved in the design and organization of the study, interpretation of the results, and the preparation of the manuscript. All authors have read and approved the final manuscript.

\section{Acknowledgements}

The work was supported by the grants from Albert Påhlsson Foundation, Swedish Nutrition Foundation, and the University Hospital of Lund University. Dr. Åke Nilsson is thanked for valuable and constructive discussions. 


\section{Author Details}

Gastroenterology and Nutrition Laboratory, Biomedical Center B11, Institution of Clinical Sciences, University of Lund, Lund, Sweden

Received: 8 March 2010 Accepted: 19 April 2010

Published: 19 April 2010

\section{References}

1. Lu K, Lee MH, Patel SB: Dietary cholesterol absorption; more than just bile. Trends Endocrinol Metab 2001, 12(7):314-320.

2. Kruit JK, Groen AK, van Berkel TJ, Kuipers F: Emerging roles of the intestine in control of cholesterol metabolism. World J Gastroenterol 2006, 12(40):6429-6439.

3. Gylling H, Miettinen TA: The effect of cholesterol absorption inhibition on low density lipoprotein cholesterol level. Atherosclerosis 1995, 117(2):305-308

4. Altmann SW, Davis HR Jr, Zhu LJ, Yao X, Hoos LM, Tetzloff G, lyer SP, Maguire M, Golovko A, Zeng M, et al:: Niemann-Pick C1 Like 1 protein is critical for intestinal cholesterol absorption. Science 2004, 303(5661):1201-1204

5. Garcia-Calvo M, Lisnock J, Bull HG, Hawes BE, Burnett DA, Braun MP, Crona $J \mathrm{H}$, Davis HR Jr, Dean DC, Detmers PA, et al.: The target of ezetimibe is Niemann-Pick C1-Like 1 (NPC1L1). Proc Natl Acad Sci USA 2005, 102(23):8132-8137.

6. Anto RJ, Mukhopadhyay A, Denning K, Aggarwal BB: Curcumin (diferuloylmethane) induces apoptosis through activation of caspase8 , BID cleavage and cytochrome $c$ release: its suppression by ectopic expression of Bcl-2 and Bcl-xl. Carcinogenesis 2002, 23(1):143-150.

7. Cheng Y, Kozubek A, Ohlsson L, Sternby B, Duan RD: Curcumin decreases acid sphingomyelinase activity in colon cancer Caco-2 cells. Planta Med 2007, 73(8):725-730.

8. Sandur SK, Ichikawa H, Pandey MK, Kunnumakkara AB, Sung B, Sethi G, Aggarwal BB: Role of pro-oxidants and antioxidants in the antiinflammatory and apoptotic effects of curcumin (diferuloylmethane). Free Radic Biol Med 2007, 43(4):568-580

9. Rao DS, Sekhara NC, Satyanarayana MN, Srinivasan M: Effect of curcumin on serum and liver cholesterol levels in the rat. J Nutr 1970, 100(11):1307-1315.

10. Asai A, Miyazawa T: Dietary curcuminoids prevent high-fat diet-induced lipid accumulation in rat liver and epididymal adipose tissue. J Nutr 2001, 131(11):2932-2935.

11. Babu PS, Srinivasan K: Hypolipidemic action of curcumin, the active principle of turmeric (Curcuma longa) in streptozotocin induced diabetic rats. Mol Cell Biochem 1997, 166(1-2):169-175.

12. Ramirez-Tortosa MC, Mesa MD, Aguilera MC, Quiles JL, Baro L, RamirezTortosa CL, Martinez-Victoria E, Gil A: Oral administration of a turmeric extract inhibits LDL oxidation and has hypocholesterolemic effects in rabbits with experimental atherosclerosis. Atherosclerosis 1999, 147(2):371-378

13. Alwi I, Santoso T, Suyono S, Sutrisna B, Suyatna FD, Kresno SB, Ernie S: The effect of curcumin on lipid level in patients with acute coronary syndrome. Acta Med Indones 2008, 40(4):201-210.

14. Baum L, Cheung SK, Mok VC, Lam LC, Leung VP, Hui E, Ng CC, Chow M, Ho PC, Lam S, et al:: Curcumin effects on blood lipid profile in a 6-month human study. Pharmacol Res 2007, 56(6):509-514.

15. Soni KB, Kuttan R: Effect of oral curcumin administration on serum peroxides and cholesterol levels in human volunteers. Indian J Physiol Pharmacol 1992, 36(4):273-275.

16. Peschel $D$, Koerting R, Nass $N$ : Curcumin induces changes in expression of genes involved in cholesterol homeostasis. J Nutr Biochem 2007, 18(2):113-119.

17. Dou X, Fan C, Wo L, Yan J, Qian Y, Wo X: Curcumin up-regulates LDL receptor expression via the sterol regulatory element pathway in HepG2 cells. Planta Med 2008, 74(11):1374-1379.

18. Gibson KM, Hoffmann G, Schwall A, Broock RL, Aramaki S, Sweetman L, Nyhan WL, Brandt IK, Wappner RS, Lehnert W, et al.: 3-Hydroxy-3methylglutaryl coenzyme A reductase activity in cultured fibroblasts from patients with mevalonate kinase deficiency: differential response to lipid supplied by fetal bovine serum in tissue culture medium. $J$ Lipid Res 1990, 31(3):515-521.

19. Field FJ, Shreves T, Fujiwara D, Murthy S, Albright E, Mathur SN: Regulation of gene expression and synthesis and degradation of 3-hydroxy-3- methylglutaryl coenzyme A reductase by micellar cholesterolin $\mathrm{CaCo}-$ 2 cells. J Lipid Res 1991, 32(11):1811-1821.

20. Eckhardt ER, Wang DQ, Donovan JM, Carey MC: Dietary sphingomyelin suppresses intestinal cholesterol absorption by decreasing thermodynamic activity of cholesterol monomers. Gastroenterology 2002, 122(4):948-956.

21. Duan RD, Bergman T, Xu N, Wu J, Cheng Y, Duan J, Nelander S, Palmberg C, Nilsson A: Identification of Human Intestinal Alkaline Sphingomyelinase as a Novel Ecto-enzyme Related to the Nucleotide Phosphodiesterase Family. J Biol Chem 2003, 278(40):38528-38536.

22. Aggarwal BB, Sung B: Pharmacological basis for the role of curcumin in chronic diseases: an age-old spice with modern targets. Trends Pharmacol Sci 2009, 30(2):85-94.

23. Duvoix A, Blasius R, Delhalle S, Schnekenburger M, Morceau F, Henry E, Dicato M, Diederich M: Chemopreventive and therapeutic effects of curcumin. Cancer Lett 2005, 223(2):181-190.

24. Sharma RA, Gescher AJ, Steward WP: Curcumin: the story so far. Eur $J$ Cancer 2005, 41(13):1955-1968.

25. Valasek MA, Repa JJ, Quan G, Dietschy JM, Turley SD: Inhibiting intestinal NPC1L1 activity prevents diet-induced increase in biliary cholesterol in Golden Syrian hamsters. Am J Physiol Gastrointest Liver Physiol 2008 , 295(4):G813-822.

26. Jesch ED, Seo JM, Carr TP, Lee JY: Sitosterol reduces messenger RNA and protein expression levels of Niemann-Pick C1-like 1 in FHs 74 Int cells. Nutr Res 2009, 29(12):859-866.

27. Alvaro A, Rosales R, Masana L, Vallve JC: Polyunsaturated fatty acids down-regulate in vitro expression of the key intestinal cholesterol absorption protein NPC1L1: no effect of monounsaturated nor saturated fatty acids. J Nutr Biochem 2009.

28. Huang $Y$, Zheng Y: The probiotic Lactobacillus acidophilus reduces cholesterol absorption through the down-regulation of Niemann-Pick C1-like 1 in Caco-2 cells. Br J Nutr 2009:1-6.

29. Iwayanagi Y, Takada T, Suzuki H: HNF4alpha is a crucial modulator of the cholesterol-dependent regulation of NPC1L1. Pharm Res 2008, 25(5):1134-1141.

30. Shishodia S, Singh T, Chaturvedi MM: Modulation of transcription factors by curcumin. Adv Exp Med Biol 2007, 595:127-148.

doi: 10.1186/1476-511X-9-40

Cite this article as: Feng et al., Curcumin inhibits cholesterol uptake in Caco2 cells by down-regulation of NPC1L1 expression Lipids in Health and Disease 2010, $9: 40$

\section{Submit your next manuscript to BioMed Centra and take full advantage of:}

- Convenient online submission

- Thorough peer review

- No space constraints or color figure charges

- Immediate publication on acceptance

- Inclusion in PubMed, CAS, Scopus and Google Scholar

- Research which is freely available for redistribution 